\title{
Statins and pancreatic cancer (Review)
}

\author{
JUN GONG ${ }^{1}$, ESHA SACHDEV ${ }^{2}$, LORI A. ROBBINS ${ }^{2}$, EMILY LIN $^{3}$, \\ ANDREW E. HENDIFAR ${ }^{4}$ and MONICA M. MITA ${ }^{5}$ \\ ${ }^{1}$ Department of Medical Oncology, City of Hope National Medical Center, Duarte, CA 91010; \\ ${ }^{2}$ Department of Internal Medicine, Cedars-Sinai Medical Center, Los Angeles, CA 90048; \\ ${ }^{3}$ Department of Internal Medicine, Harbor-UCLA Medical Center, Torrance, CA 90509; ${ }^{4}$ Department of Internal Medicine, \\ Division of Medical Oncology and ${ }^{5}$ Experimental Therapeutics Program, \\ Samuel Oschin Comprehensive Cancer Institute, Cedars-Sinai Medical Center, Los Angeles, CA 90048, USA
}

Received April 11, 2016; Accepted September 22, 2016

DOI: $10.3892 / \mathrm{ol} .2017 .5572$

\begin{abstract}
Pancreatic cancer remains among the most lethal cancers, despite ongoing advances in treatment for all stages of the disease. Disease prevention represents another opportunity to improve patient outcome, with metabolic syndrome and its components, such as diabetes, obesity and dyslipidemia, having been recognized as modifiable risk factors for pancreatic cancer. In addition, statins have been shown to potentially reduce pancreatic cancer risk and to improve survival in patients with a combination of metabolic syndrome and pancreatic cancer. Furthermore, preclinical studies have demonstrated that statins exhibit antitumor effects in pancreatic cancer cell lines in vitro and animal models in vivo, in addition to delaying the progression of pancreatic intraepithelial neoplasia to pancreatic ductal adenocarcinoma (PDAC) and inhibiting PDAC formation in conditional K-Ras mutant mice. The mechanisms by which statins produce anticancer effects remain poorly understood, although appear to involve inhibition of the mevalonate/cholesterol synthesis pathway, thus blocking the synthesis of intermediates important for prenylation and activation of the Ras/mitogen-activated protein kinase 1 signaling pathway. Furthermore, statins have been identified to modulate the phosphoinositide 3-kinase/Akt serine/threonine kinase 1 and inflammation signaling pathways, and to alter the expression of genes involved in lipid metabolism, which are important for PDAC growth and proliferation. In addition, statins have been demonstrated to exhibit further antitumor mechanisms in a number of other cancer types, which are beyond the scope of the present review. In the present review, current evidence highlighting the potential
\end{abstract}

Correspondence to: Dr Monica M. Mita, Experimental Therapeutics Program, Samuel Oschin Comprehensive Cancer Institute, Cedars-Sinai Medical Center, 8700 Beverly Boulevard, Saperstein Critical Care Tower, Suite MS 35, Los Angeles, CA 90048, USA

E-mail: monica.mita@cshs.org

Key words: pancreatic cancer, statins, chemoprevention, obesity, metabolic syndrome of statins as chemopreventive agents in pancreatic cancer is presented, and the antitumor mechanisms of statins elucidated thus far in this disease are discussed.

\section{Contents}

1. Introduction

2. Metabolic syndrome and pancreatic cancer risk

3. Statins and pancreatic cancer

4. Mechanisms of action and evidence of antitumor effects of statins in pancreatic cancer

5. Conclusions

\section{Introduction}

Pancreatic cancer is relatively rare, with an incidence of $\sim 12$ cases per 100,000 people in the USA and 2-8 cases per 100,000 people worldwide $(1,2)$. However, pancreatic cancer is the fourth-leading cause of cancer mortalities in men and women in the USA, and the eighth- and ninth- leading cause of cancer mortalities in men and women worldwide, respectively $(2,3)$. Pancreatic ductal adenocarcinoma (PDAC) accounts for $85 \%$ of all pancreatic cancer cases (4). The disease tends to occur in the elderly and present at an advanced stage, with a median age at diagnosis of 71 years old, and $<20 \%$ of cases presenting with localized and resectable tumors $(4,5)$. Advances in treatment, specifically multi-agent chemotherapy, have improved survival rates, which were previously poor in those with advanced and metastatic pancreatic cancer (4). In addition, adjuvant therapy has been shown to confer a survival advantage compared with postoperative observation alone in resected pancreatic cancer (4-6). However, despite these advances, pancreatic cancer remains among the most lethal cancers, with a 5-year survival rate of 6-7\% across all stages (1).

In an effort to improve outcomes via disease prevention, a growing body of research has focused on the environmental risk factors for pancreatic cancer (7-9). The association between pancreatic cancer and modifiable risk factors with moderate/strong evidence of association, including tobacco 
use, alcoholism and dietary intake, has been extensively reviewed $(8,9)$. It has been estimated that $\sim 2 / 3$ of the major risk factors for pancreatic cancer are potentially modifiable (9). Furthermore, there is evidence to suggest that $1 / 3$ of the burden of pancreatic cancer may be prevented through the application of this knowledge (9). Evidence for the chemopreventive effects of medications typically used to treat non-cancer-related and chronic conditions is increasing (10). In particular, the potential application of statins as a chemopreventive agent for pancreatic cancer is an area of increasing interest and is evaluated in the present review.

\section{Metabolic syndrome and pancreatic cancer risk}

The presence of metabolic syndrome, defined in one meta-analysis as the co-occurrence of $\geq 3$ medical conditions, including diabetes, hypertension, hyperlipidemia, and a body mass index (BMI) $\geq 25 \mathrm{~kg} / \mathrm{m}^{2}$, has been shown to be associated with a relative risk (RR) for pancreatic cancer of 1.55 [95\% confidence interval (CI), 1.19-2.01], with a greater risk for those patients with more components of the syndrome (11). In addition, meta-analyses have shown a stronger association between pancreatic cancer and metabolic syndrome in women (11-13). Furthermore, individual components of metabolic syndrome have been identified as modifiable risk factors for pancreatic cancer. For example, diabetes as a risk factor for the development of pancreatic cancer, leading to the assessment of metformin as a potential chemopreventive agent for this cancer (14).

Several pooled analyses and meta-analyses have demonstrated that obesity is a risk factor for pancreatic cancer, with a $\mathrm{RR}$ of $<1.47$ (95\% CI, 1.23-1.75) in those with a BMI $\geq 30 \mathrm{~kg} / \mathrm{m}^{2}$, and which is often independent of other risk factors, such as age, gender, diabetes and smoking status $(8,9,15-21)$. The RR for pancreatic cancer following an increase of 5 units in BMI, $10 \mathrm{~cm}$ in waist circumference and 0.1 unit in waist-to-hip ratio has been shown to be 1.10 (95\% CI, 1.07-1.14), 1.11 (95\% CI, 1.05-1.18) and 1.19 (95\% CI, 1.09-1.31), respectively (20). Compared with individuals who were not overweight (BMI $<25 \mathrm{~kg} / \mathrm{m}^{2}$ ) or obese (BMI $<30 \mathrm{~kg} / \mathrm{m}^{2}$ ) in early adulthood (defined as age 18 or 21 years), the risk for pancreatic cancer was higher in those who were overweight or obese in early adulthood (RR, 1.54; 95\% CI, 1.24-1.93) (19). Furthermore, pancreatic cancer risk was greater (RR, 1.40; 95\% CI, $1.13-1.72$ ) in those who gained $\geq 10 \mathrm{~kg} / \mathrm{m}^{2}$ in BMI at baseline and early adulthood compared with those whose BMI remained stable (19). However, BMI does not appear to be associated with risk of mortality from pancreatic cancer in the Asian population, following adjustment for risk factors, including age, smoking status and diabetes (22).

Fatty infiltration of the pancreas, which is determined histopathologically, appears to be a risk factor for pancreatic intraepithelial neoplasias (PanINs) and PDAC, with BMI being the most significantly associated factor with pancreatic fatty infiltration $(23,24)$. Notably, circulating levels of adiponectin, an adipocyte-secreted hormone with insulin sensitizing and anti-inflammatory properties, has been revealed to be inversely correlated with pancreatic cancer risk, independent of other risk factors (25). Notably, meta-analyses of other anthropometric measures such as physical activity have primarily produced non-significant findings in relation to protective effects against pancreatic cancer (26-28). Consistent physical activity over time was demonstrated to have a greater association with pancreatic cancer risk reduction (RR, $0.86 ; 95 \% \mathrm{CI}$, 0.76-0.97) compared with recent (RR, 0.95; 95\% CI, 0.90-1.01) and distant (RR, 0.95; 95\% CI, 0.79-1.15) past physical activity alone (28).

Abnormal lipid metabolism, which can cause high levels of total cholesterol and triglycerides, or low levels of high-density lipoprotein and apolipoprotein A-I, has been identified to be associated with an increased risk of obesity-related cancers, including pancreatic cancer, in a meta-analysis (29). A separate pooled analysis and meta-analysis demonstrated that total serum cholesterol is inversely correlated with pancreatic cancer risk in men (30) and the European population (31). In addition, meta-analyses have shown that a high dietary intake of cholesterol is significantly associated with risk for pancreatic cancer, particularly in the American and European populations, with RRs <1.371 (95\% CI, 1.155-1.627), following adjustment for confounding factors $(31,32)$. Furthermore, pancreatic cancer risk rises by $8 \%$ with an increased intake in cholesterol of $100 \mathrm{mg} /$ day (RR, 1.08; 95\% CI, 1.04-1.13), in what was determined to a linear dose-response association (32). Total dietary fat consumption was reported to be independently associated with pancreatic cancer risk according to one meta-analysis (33), although this has been refuted (8). Results regarding the association between omega-3 polyunsaturated fatty acid consumption and pancreatic cancer risk/survival are mixed $(34,35)$.

\section{Statins and pancreatic cancer}

Epidemiologic evidence for the association between statins and pancreatic cancer risk remains controversial. Several epidemiologic studies, including two meta-analyses, have suggested that statin use, regardless of dose, duration or type (lipophilic, such as atorvastatin, lovastatin and simvastatin, or hydrophilic, such as pravastatin, rosuvastatin and fluvastatin), does not significantly affect pancreatic cancer risk (36-40). However, significant heterogeneity was detected among the included studies $(36,40)$. Conversely, a dose-response association was identified between statin use and pancreatic cancer risk with an $80 \%$ reduced pancreatic cancer risk [odds ratio (OR), 0.20; 95\% CI, 0.13-0.29] in those with $>4$ years statin use, irrespective of age, gender, ethnicity, BMI, diabetes, smoking status or alcohol use (41). Furthermore, in a matched case-control study, male smokers who were regular statin users had a significantly reduced OR for pancreatic cancer (42). In a large case-control study (1,405 participants), statin use in men (OR, 0.50; 95\% CI, 0.32-0.79) and a duration of statin use of $>10$ years (OR, $0.51 ; 95 \%$ CI, $0.31-0.85)$ were significantly associated with a reduced risk of pancreatic cancer (43).

Notably, preoperative use of statins has been demonstrated to be a predictor of increased early postoperative mortality in patients with resected pancreatic cancer (44). However, one study reported that statins improved the survival [hazard ratio (HR), 0.40; $\mathrm{P}=0.010$ ] of patients with diabetes who were undergoing chemotherapy for advanced pancreatic cancer (45). Furthermore, patients with metabolic syndrome and pancreatic cancer on hydrophilic statins exhibited increased survival 
(HR, 0.67; 95\% CI, 0.46-0.96) compared with those not on statins (46).

\section{Mechanisms of action and evidence of antitumor effects of statins in pancreatic cancer}

Early evidence demonstrated that lovastatin and simvastatin, inhibitors of 3-hydroxy-3-methylglutaryl-coenzyme A (HMG-CoA) reductase, the rate-limiting enzyme in the mevalonate/cholesterol synthesis pathway, inhibited tumor growth in a number of human and rodent pancreatic cancer cell lines in vitro and tumor xenografts in mice in vivo, through cell cycle arrest in G1 and inhibition of DNA synthesis, and that this process was reversed by adding mevalonic acid (47-49). In addition, lovastatin was noticed to induce $\mathrm{G} 1$ and $\mathrm{G} 2 / \mathrm{M}$ cell cycle arrest, thus inhibiting tumor growth in vitro in a dose-dependent manner, which was possibly independent of K-Ras mutational status, and to significantly decrease post-translational phosphorylation of the Ras protein in K-Ras mutant human pancreatic cancer cells (50). Furthermore, the results of another study indicated that statins exerted direct cytotoxic effects in human pancreatic cancer cells via pro-apoptotic activity (51).

Fluvastatin was identified to inhibit epidermal growth factor (EGF)-induced invasion of human pancreatic cancer cells in vitro, and to reduce metastatic tumor formation and growth in vivo at the dose recommended for the treatment of hypercholesterolemia in humans $(52,53)$. Specifically, fluvastatin prevents geranylgeranylation of RhoA, a member of the Rho subfamily of small guanosine triphosphatases that are involved in cell motility, structure and invasion $(52,53)$. Geranylgeranylation is a form of post-translational modification known as prenylation, by which isoprene units from an isoprenoid intermediate of the mevalonate/cholesterol synthesis pathway such as geranylgeranyl pyrophosphate are attached to target proteins $(52,53)$. Inhibition of geranylgeranylation of RhoA inhibits EGF-induced translocation of RhoA from the cytoplasm to the plasma membrane and its subsequent activation $(52,53)$. In a separate study, fluvastatin was shown to inhibit farnesylation [the attachment of a lipophilic farnesyl group from farnesyl pyrophosphate (FPP) to a cysteine residue at the C-terminus of a target protein] of Ras in a dose-dependent manner, a process critical for the membrane translocation and subsequent activation of Ras, which is involved in cell growth, proliferation and survival (Fig. 1) (54). In addition, fluvastatin reduces phosphorylation and activation of mitogen-activated protein kinase 1 (MAPK1)/extracellular signal-regulated kinase 2 (ERK2), a downstream effector of Ras, and synergizes with gemcitabine to significantly inhibit tumor growth in vitro and in vivo through increasing the expression of an enzyme required for the activation of gemcitabine (54).

The importance of isoprenoid synthesis and prenylation in pancreatic cancer growth was reinforced when lovastatin in combination with pamidronate, an inhibitor of FPP synthase, was demonstrated to inhibit farnesylation and geranylgeranylation, and to exhibit synergistic antitumor effects in vitro and in vivo (55). Furthermore, statins were shown to improve survival and reduce tumor burden in animal models of pancreatic cancer compared with controls at doses below the maximum recommended dose for humans (56). Tumor tissues from K-Ras mutant mice treated with atorvastatin displayed significantly decreased levels of membrane-bound K-Ras and phosphorylated Raf (56). In addition, an analysis of pancreatic cancer cell lines treated with atorvastatin in vitro demonstrated a dose-dependent reduction in the activation of downstream effectors of Ras, including Raf, ERK1/2, Jun and p90 ribosomal s6 kinase, and an inhibition of targets of prenylation that are important for protein-protein interactions and carcinogenesis, such as human DnaJ homolog and nuclear prelamin A (56). Of note, in vitro gene array analysis revealed that atorvastatin modulated the expression of 132 genes, including those involved in inflammation, such as cytochrome P450 family 51 subfamily A member 1, soluble epoxide hydrolase and vascular adhesion molecule 1 (Fig. 1) (56).

Simvastatin and atorvastatin have been shown to significantly delay the progression of PanIN lesions to PDAC and to inhibit PDAC growth in conditional K-Ras mutant mice $(57,58)$. In one study, treatment with atorvastatin resulted in significantly downregulated expression of components of the Ras/MAPK, phosphoinositide 3-kinase (PI3K)/Akt and nuclear factor- $\mathrm{\kappa B}(\mathrm{NF}-\mathrm{\kappa B})$ signaling pathways, including Akt, phosphorylated (p) Akt, purinergic receptor P2X7, RhoA, pERK, cyclin dependent kinase 2 , cyclin D1, $\beta$-catenin, cyclin E, survivin, caveolin-1, granulocyte-macrophage colony-stimulating factor, cyclooxygenase-2 (COX-2), and interleukin (IL)-2, -6 and -12 in vivo (Fig. 1) (58). The ability of atorvastatin to inhibit PI3K/Akt, Ras/MAPK and NF- $\mathrm{KB}$ signaling may be dependent on the underexpression of $\mathrm{P} 2 \mathrm{X} 7$, at least in human pancreatic cancer cells in vitro (59). Combined inhibition of HMG-CoA reductase, COX-2 and farnesyl transferase in human pancreatic cancer cell lines in vitro was observed to inhibit tumor growth and to produce a stronger decrease in pAkt and pERK1/2 levels compared with each agent alone (60). A summary of the antitumor mechanisms of statins in pancreatic cancer from existing evidence is shown in Fig. 1.

The association between statins, lipid metabolism and PDAC development continues to grow in complexity. A previous study identified a potential role for simvastatin-induced accumulation of cytosolic lipid droplets and upregulation of genes involved in lipid metabolism [such as ATP-binding cassette (ABC) A7] and triacylglycerole and phospholipid synthesis (such as 1-acylglycerol-3-phosphate O-acyltransferase 2) in the apoptosis of pancreatic cancer cells in vitro (61). Oxysterol binding protein-like 5 (ORP5) has been associated with increased pancreatic cancer invasion, stimulation of cholesterol synthesis via expression of sterol response element binding protein 2 (SREBP2) and regulation of the effects of statins in human PDAC cells in vitro (62). High doses of statins were required for growth inhibition in cancer cells strongly expressing ORP5, while only low doses were required in cells with moderate expression (62). In addition, a growing body of research has identified that targeting mediators of mevalonate/cholesterol synthesis and lipid metabolism other than HMG-CoA reductase with statins or alternative inhibitors modulates chemotherapy and radiation resistance in pancreatic cancer, and suppresses pancreatic cancer growth and metastasis (63-67).

A recent preclinical study highlighted that the majority of activated pro-tumorigenic metabolic pathways in K-Ras mutant mouse models of PDAC were involved in lipid 


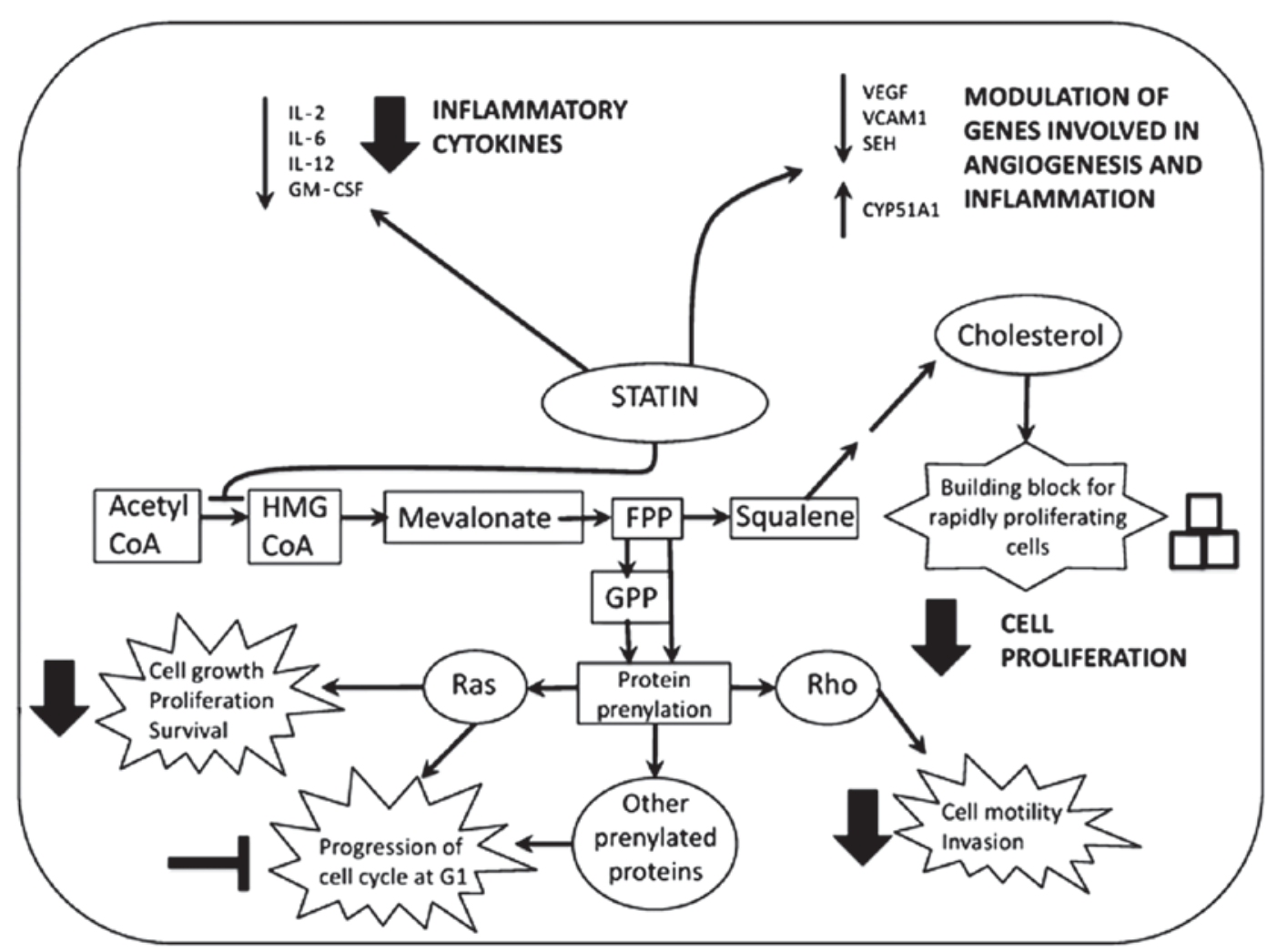

Figure 1. Mechanism of action of statins in pancreatic cancer. Statins decrease the expression of inflammatory cytokines and modulate the expression of a number of genes involved in angiogenesis and inflammation, which may protect against carcinogenesis. In addition, statins inhibit protein prenylation. This prevents the proper functioning of guanosine triphosphatase proteins such as Ras and Rho, thus inhibiting downstream pathways that are involved in cell growth, proliferation, survival, motility and invasion, which leads to cell cycle arrest in G1. Furthermore, statins impair cancer cell proliferation by inhibiting the synthesis of cholesterol, which is essential for new membrane formation in rapidly proliferating cells. IL, interleukin; GM-CSF, granulocyte macrophage colony-stimulating factor; VEGF, vascular endothelial growth factor; VCAM1, vascular cell adhesion molecule 1; SEH, soluble epoxide hydrolase; CYP51A1, cytochrome P450 family 51 subfamily A member 1; Acetyl-CoA, acetyl-coenzyme A; HMG-CoA, 3-hydroxy-3-methylglutaryl-coenzyme A; FPP, farnesyl pyrophosphate; GPP, geranyl pyrophosphate.

metabolism compared with control mice (68). In particular, the expression of low-density lipoprotein receptor (LDLR), apolipoprotein (Apo) B, ApoE, ABCA1, SREBP2, HMG-CoA reductase, cholesterol acyltransferase 1 , lipase $\mathrm{A}$, and other transcripts involved in the synthesis/uptake of cholesterol and its derivatives (including oxysterols and steroid hormones) was significantly increased in PDAC compared with control pancreas in mouse models in vivo, illustrating the high dependence of pancreatic cancer cells on cholesterol (68). In addition, an increase in total cholesterol, cholesterol ester (CE) and free cholesterol (FC) content was observed in pancreatic tumors compared with healthy pancreas (68). Knockdown of LDLR expression in vitro via short hairpin RNA was demonstrated to inhibit cell proliferation, enhance the cytotoxic effects of chemotherapy and redistribute total cholesterol content (reduce CE and increase FC) in PDAC, without compensatory overactivation of cholesterol synthesis (68). Furthermore, enhanced LDLR expression appears to be an indicator of poor prognosis in human PDAC, regardless of cancer stage (68).

The existence of differential effects between hydrophobic statins such as simvastatin and hydrophilic statins such as pravastatin have been proposed, as simvastatin appears to produce greater antitumor effects compared with pravastatin in several cancer cell lines (excluding pancreatic) in vitro (69). However, another study demonstrated that, although simvastatin produced the greatest antitumor effects in vitro, rosuvastatin, cerivastatin and fluvastatin had the most potent antitumor effects in animal models of PDAC at the recommended human doses, with all statins (hydrophobic and hydrophilic) except pravastatin exerting inhibitory effects on intracellular Ras translocation (70). Conversely, a phase II trial involving 114 patients with locally advanced and metastatic pancreatic cancer revealed that patients who received 3 weeks of gemcitabine $\left(1,000 \mathrm{mg} / \mathrm{m}^{2}\right.$ on days 1,8 and 15$)$ and simvastatin (40 mg once daily) had no clinical benefit compared with patients treated with gemcitabine alone, although there was no increase in toxicity from the combined treatment (71).

\section{Conclusions}

Although statins in combination with chemotherapy have failed to demonstrate improved antitumor efficacy based on recent clinical evidence, the data are limited to just a few clinical trials in patients with advanced and metastatic PDAC (71). The attractiveness of statins as a component of chemotherapeutic regimens for pancreatic cancer lies in their relatively safe and well-tolerated toxicity profile and low cost (10). For this reason, further clinical trials are warranted to better define the potential of statins as an adjunct to standard chemotherapy for the treatment of pancreatic cancer. Aside from treatment, disease prevention represents another opportunity to improve patient outcomes in pancreatic cancer. Metabolic syndrome 
and its components, including diabetes, obesity and dyslipidemia, have been recognized as modifiable risk factors for pancreatic cancer $(72,73)$. Evidence discussed in the present review has demonstrated that statins potentially reduce pancreatic cancer risk and improve survival in patients with a combination of metabolic syndrome and pancreatic cancer. Furthermore, preclinical studies suggest that statins exhibit antitumor effects in pancreatic cancer cell lines in vitro and in animal models in vivo, in addition to delaying the progression of PanIN lesions to PDAC and inhibiting PDAC formation in conditional K-Ras mice models. However, the mechanisms by which statins elicit these effects remain poorly understood, although recent evidence postulates that statins inhibit the mevalonate/cholesterol synthesis pathway, thus blocking the formation of intermediates that are critical for prenylation and activation of Ras/MAPK, PI3K/Akt and associated signaling pathways (10). In addition, statins appear to modulate lipid metabolism and inflammation signaling pathways, which are important for pancreatic cancer growth and progression (73). In conclusion, it is evident that further studies are required to elucidate the mechanisms underlying the anticancer effects of statins in PDAC. Nevertheless, increasing evidence supports the potential application of statins as a chemopreventive agent in pancreatic cancer.

\section{References}

1. Howlader N, Noone AM, Krapcho M, Garshell J, Neyman N, Altekruse SF, et al: (eds): SEER Cancer Statistics Review, 1975-2011, National Cancer Institute. Bethesda, MD: http://seer. cancer.gov/csr/1975_2011/, 2014.

2. Jemal A, Bray F, Center MM, Ferlay J, Ward E and Forman D: Global cancer statistics. CA Cancer J Clin 61: 69-90, 2011.

3. Siegel RL, Miller KD and Jemal A: Cancer statistics, 2015. CA Cancer J Clin 65: 5-29, 2015.

4. Ryan DP, Hong TS and Bardeesy N: Pancreatic adenocarcinoma. N Engl J Med 371: 1039-1049, 2014.

5. Hidalgo M: Pancreatic cancer. N Engl J Med 362: 1605-1617, 2010

6. Wolfgang CL, Herman JM, Laheru DA, Klein AP, Erdek MA, Fishman EK and Hruban RH: Recent progress in pancreatic cancer. CA Cancer J Clin 63: 318-348, 2013.

7. Lowenfels $\mathrm{AB}$ and Maisonneuve P: Can we prevent pancreatic disease? Clin Gastroenterol Hepatol 12: 1645-1646, 2014.

8. Alsamarrai A, Das SL, Windsor JA and Petrov MS: Factors that affect risk for pancreatic disease in the general population: A systematic review and meta-analysis of prospective cohort studies. Clin Gastroenterol Hepatol 12: 1635.e5-1644.e5; quiz e103, 2014.

9. Maisonneuve P and Lowenfels AB: Risk factors for pancreatic cancer: A summary review of meta-analytical studies. Int J Epidemiol 44: 186-198, 2015.

10. Gronich N and Rennert G: Beyond aspirin-cancer prevention with statins, metformin and bisphosphonates. Nat Rev Clin Oncol 10: 625-642, 2013

11. Rosato V, Tavani A, Bosetti C, Pelucchi C, Talamini R, Polesel J, Serraino D, Negri E and La Vecchia C: Metabolic syndrome and pancreatic cancer risk: A case-control study in Italy and meta-analysis. Metabolism 60: 1372-1378, 2011.

12. Esposito K, Chiodini P, Colao A, Lenzi A and Giugliano D: Metabolic syndrome and risk of cancer: A systematic review and meta-analysis. Diabetes Care 35: 2402-2411, 2012.

13. Stocks T, Bjørge T, Ulmer H, Manjer J, Häggström C, Nagel G, Engeland A, Johansen D, Hallmans G, Selmer R, et al: Metabolic risk score and cancer risk: Pooled analysis of seven cohorts. Int J Epidemiol 44: 1353-1363, 2015.

14. Gong J, Robbins LA, Lugea A, Waldron RT, Jeon CY and Pandol SJ: Diabetes, pancreatic cancer, and metformin therapy. Front Physiol 5: 426, 2014.

15. Berrington de Gonzalez A, Sweetland S and Spencer E: A meta-analysis of obesity and the risk of pancreatic cancer. Br J Cancer 89: 519-523, 2003.
16. Larsson SC, Orsini $\mathrm{N}$ and Wolk A: Body mass index and pancreatic cancer risk: A meta-analysis of prospective studies. Int J Cancer 120: 1993-1998, 2007.

17. Arslan AA, Helzlsouer KJ, Kooperberg C, Shu XO, Steplowski E, Bueno-de-Mesquita HB, Fuchs CS, Gross MD, Jacobs EJ, Lacroix AZ, et al: Anthropometric measures, body mass index and pancreatic cancer: A pooled analysis from the Pancreatic Cancer Cohort Consortium (PanScan). Arch Intern Med 170: 791-802, 2010

18. Jiao L, Berrington de Gonzalez A, Hartge P, Pfeiffer RM, Park Y, Freedman DM, Gail MH, Alavanja MC, Albanes D, Beane Freeman LE, et al: Body mass index, effect modifiers, and risk of pancreatic cancer: A pooled study of seven prospective cohorts. Cancer Causes Control 21: 1305-1314, 2010.

19. Genkinger JM, Spiegelman D, Anderson KE, Bernstein L, van den Brandt PA, Calle EE, English DR, Folsom AR, Freudenheim JL, Fuchs CS, et al: A pooled analysis of 14 cohort studies of anthropometric factors and pancreatic cancer risk. Int J Cancer 129: 1708-1717, 2011.

20. Aune D, Greenwood DC, Chan DS, Vieira R, Vieira AR, Navarro Rosenblatt DA, Cade JE, Burley VJ and Norat T: Body mass index, abdominal fatness and pancreatic cancer risk: A systematic review and non-linear dose-response meta-analysis of prospective studies. Ann Oncol 23: 843-852, 2012.

21. Bethea TN, Kitahara CM, Sonderman J, Patel AV, Harvey C, Knutsen SF, Park Y, Park SY, Fraser GE, Jacobs EJ, et al: A pooled analysis of body mass index and pancreatic cancer mortality in African Americans. Cancer Epidemiol Biomarkers Prev 23: 2119-2125, 2014.

22. Lin Y, Fu R, Grant E, Chen Y, Lee JE, Gupta PC, Ramadas K, Inoue M, Tsugane S, Gao YT, et al: Association of body mass index and risk of death from pancreatic cancer in Asians: Findings from the Asia Cohort Consortium. Eur J Cancer Prev 22: 224-250, 2013.

23. Hori M, Takahashi M, Hiraoka N, Yamaji T, Mutoh M, Ishigamori R, Furuta K, Okusaka T, Shimada K, Kosuge T, et al: Association of pancreatic fatty infiltration with pancreatic ductal adenocarcinoma. Clin Transl Gastroenterol 5: e53, 2014.

24. Rebours V, Gaujoux S, d'Assignies G, Sauvanet A, Ruszniewski P, Levy P, Bedossa P, Paradis V and Couvelard A: Obesity and fatty pancreatic infiltration are risk factors for pancreatic precancerous lesions (PanIN). Clin Cancer Res 21: 3522-3528, 2015.

25. Bao Y, Giovannucci EL, Kraft P, Stampfer MJ, Ogino S, Ma J, Buring JE, Sesso HD, Lee IM, Gaziano JM, et al: A prospective study of plasma adiponectin and pancreatic cancer risk in five US cohorts. J Natl Cancer Inst 105: 95-103, 2013.

26. Bao Y and Michaud DS: Physical activity and pancreatic cancer risk: A systematic review. Cancer Epidemiol Biomarkers Prev 17: 2671-2682, 2008

27. O'Rorke MA, Cantwell MM, Cardwell CR, Mulholland HG and Murray LJ: Can physical activity modulate pancreatic cancer risk? a systematic review and meta-analysis. Int J Cancer 126: 2957-2968, 2010.

28. Behrens G, Jochem C, Schmid D, Keimling M, Ricci C and Leitzmann MF: Physical activity and risk of pancreatic cancer: A systematic review and meta-analysis. Eur J Epidemiol 30: 279-298, 2015.

29. Melvin JC, Holmberg L, Rohrmann S, Loda M and Van Hemelrijck M: Serum lipid profiles and cancer risk in the context of obesity: Four meta-analyses. J Cancer Epidemiol 2013: 823849, 2013.

30. Strohmaier S, Edlinger M, Manjer J, Stocks T, Bjørge T, Borena W, Häggström C,Engeland A, Nagel G, Almquist M, et al: Total serum cholesterol and cancer incidence in the Metabolic syndrome and Cancer Project (Me-Can). PLoS One 8: e54242, 2013.

31. Chen X, Zhou T and Chen M: Meta analysis of the association of cholesterol with pancreatic carcinoma risk. J BUON 20: 109-113, 2014.

32. Chen H, Qin S, Wang M, Zhang T and Zhang S: Association between cholesterol intake and pancreatic cancer risk: Evidence from a meta-analysis. Sci Rep 5: 8243, 2015.

33. Shen QW and Yao QY: Total fat consumption and pancreatic cancer risk: A meta-analysis of epidemiologic studies. Eur J Cancer Prev 24: 278-285, 2015.

34. Qin B, Xun P and He K: Fish or long-chain (n-3) PUFA intake is not associated with pancreatic cancer risk in a meta-analysis and systematic review. J Nutr 142: 1067-1073, 2012.

35. Ma YJ, Yu J, Xiao J and Cao BW: The consumption of omega-3 polyunsaturated fatty acids improves clinical outcomes and prognosis in pancreatic cancer patients: A systematic evaluation. Nutr Cancer 67: 112-118, 2015. 
36. Bonovas S, Filioussi K and Sitaras NM: Statins are not associated with a reduced risk of pancreatic cancer at the population level, when taken at low doses for managing hypercholesterolemia: Evidence from a meta-analysis of 12 studies. Am J Gastroenterol 103: 2646-2651, 2008.

37. Bradley MC, Hughes CM, Cantwell MM and Murray LJ: Statins and pancreatic cancer risk: A nested case-control study. Cancer Causes Control 21: 2093-2100, 2010.

38. Chiu HF, Chang CC, Ho SC, Wu TN and Yang CY: Statin use and the risk of pancreatic cancer: A population-based case-control study. Pancreas 40: 669-672, 2011

39. Jacobs EJ, Newton CC, Thun MJ and Gapstur SM: Long-term use of cholesterol-lowering drugs and cancer incidence in a large United States cohort. Cancer Res 71: 1763-1771, 2011.

40. Cui X, Xie Y, Chen M, Li J, Liao X, Shen J, Shi M, Li W, Zheng $\mathrm{H}$ and Jiang B: Statin use and risk of pancreatic cancer: A meta-analysis. Cancer Causes Control 23: 1099-1111, 2012.

41. Khurana V, Sheth A, Caldito G and Barkin JS: Statins reduce the risk of pancreatic cancer in humans: A case-control study of half a million veterans. Pancreas 34: 260-265, 2007.

42. Carey FJ, Little MW, Pugh TF, Ndokera R, Ing H, Clark A, Dennison A, Metcalfe MS, Robinson RJ and Hart AR: The differential effects of statins on the risk of developing pancreatic cancer: A case-control study in two centres in the United Kingdom. Dig Dis Sci 58: 3308-3312, 2013.

43. Walker EJ, Ko AH, Holly EA and Bracci PM: Statin use and risk of pancreatic cancer: Results from a large, clinic-based case-control study. Cancer 121: 1287-1294, 2015.

44. Chagpar RB, Martin RC, Ahmad SA, Kim HJ, Rupp C, Weber S, Ebelhar A, Gilbert J, Brinkman A, Winslow E, et al: Medically managed hypercholesterolemia and insulin-dependent diabetes mellitus preoperatively predicts poor survival after surgery for pancreatic cancer. J Gastrointest Surg 15: 551-557, 2011.

45. Nakai Y, Isayama H, Sasaki T, Mizuno S, Sasahira N, Kogure H, Kawakubo K, Yamamoto N, Hirano K, Ijichi H, et al: Clinical outcomes of chemotherapy for diabetic and nondiabetic patients with pancreatic cancer: Better prognosis with statin use in diabetic patients. Pancreas 42: 202-208, 2013.

46. Jeon CY, Pandol SJ and Goodman MT: Survival time in pancreatic cancer patients with metabolic syndrome varies by use of insulin and statins. Cancer Res 74 (Suppl 19): 2173, 2014.

47. Mikulski SM, Viera A, Darzynkiewicz Z and Shogen K: Synergism between a novel amphibian oocyte ribonuclease and lovastatin in inducing cytostatic and cytotoxic effects in human lung and pancreatic carcinoma cell lines. Br J Cancer 66: 304-310, 1992.

48. Sumi S, Beauchamp RD, Townsend CM Jr, Uchida T, Murakami M, Rajaraman S, Ishizuka J and Thompson JC: Inhibition of pancreatic adenocarcinoma cell growth by lovastatin. Gastroenterology 103: 982-989, 1992.

49. Ura H, Obara T, Nishino N, Tanno S, Okamura K and Namiki M: Cytotoxicity of simvastatin to pancreatic adenocarcinoma cells containing mutant ras gene. Jpn J Cancer Res 85: 633-638, 1994

50. Müller C, Bockhorn AG, Klusmeier S, Kiehl M, Roeder C, Kalthoff $\mathrm{H}$ and Koch OM: Lovastatin inhibits proliferation of pancreatic cancer cell lines with mutant as well as with wild-type K-ras oncogene but has different effects on protein phosphorylation and induction of apoptosis. Int J Oncol 12: 717-723, 1998.

51. Kamiński R, Kozar K, Kopeć M, Basak G, Skierski JS Koronkiewicz M, Jakóbisiak M and Gołab J: Discussion on 3-hydroxy-3-methylglutaryl-coenzyme a reductase inhibitors reduce human pancreatic cancer cell invasion and metastasis. Gastroenterology 123: 1747, 2002.

52. Kusama T, Mukai M, Iwasaki T, Tatsuta M, Matsumoto $\mathrm{Y}$, Akedo $\mathrm{H}$ and Nakamura $\mathrm{H}$ : Inhibition of epidermal growth factor-induced RhoA translocation and invasion of human pancreatic cancer cells by 3-hydroxy-3-methylglutaryl-coenzyme a reductase inhibitors. Cancer Res 61: 4885-4891, 2001.

53. Kusama T, Mukai M, Iwasaki T, Tatsuta M, Matsumoto Y, Akedo H, Inoue $\mathrm{M}$ and Nakamura H: 3-hydroxy-3-methylglutaryl-coenzyme a reductase inhibitors reduce human pancreatic cancer cell invasion and metastasis. Gastroenterology 122: 308-317, 2002.

54. Bocci G, Fioravanti A, Orlandi P, Bernardini N, Collecchi P, Del Tacca M and Danesi R: Fluvastatin synergistically enhances the antiproliferative effect of gemcitabine in human pancreatic cancer MIAPaCa-2 cells. Br J Cancer 93: 319-330, 2005.

55. Issat T, Nowis D, Legat M, Makowski M, Klejman MP, Urbanski J, Skierski J, Koronkiewicz M, Stoklosa T, Brzezinska A, et al: Potentiated antitumor effects of the combination treatment with statins and pamidronate in vitro and in vivo. Int J Oncol 30: $1413-1425,2007$
56. Liao J, Chung YT, Yang AL, Zhang M, Li H, Zhang W, Yan L and Yang GY: Atorvastatin inhibits pancreatic carcinogenesis and increases survival in LSL-KrasG12D-LSL-Trp53R172H-Pd x1-Cre mice. Mol Carcinog 52: 739-750, 2013.

57. Fendrich V, Sparn M, Lauth M, Knoop R, Plassmeier L, Bartsch DK and Waldmann J: Simvastatin delay progression of pancreatic intraepithelial neoplasia and cancer formation in a genetically engineered mouse model of pancreatic cancer. Pancreatology 13: 502-507, 2013.

58. Mohammed A, Qian L, Janakiram NB, Lightfoot S, Steele VE and Rao CV: Atorvastatin delays progression of pancreatic lesions to carcinoma by regulating PI3/AKT signaling in $\mathrm{p} 48 \mathrm{Cre} /+$ LSL-KrasG12D/+ mice. Int J Cancer 131: 1951-1962, 2012.

59. Mistafa $\mathrm{O}$ and Stenius U: Statins inhibit Akt/PKB signaling via P2X7 receptor in pancreatic cancer cells. Biochem Pharmacol 78: 1115-1126, 2009.

60. Ding N, Cui XX, Gao Z, Huang H, Wei X, Du Z, Lin Y, Shih WJ, Rabson $\mathrm{AB}$, Conney $\mathrm{AH}$, et al: A triple combination of atorvastatin, celecoxib and tipifarnib strongly inhibits pancreatic cancer cells and xenograft pancreatic tumors. Int J Oncol 44: 2139-2145, 2014.

61. Gbelcová H, Svéda M, Laubertová L, Varga I, Vítek L, Kolář M, Strnad H, Zelenka J, Böhmer D and Ruml T: The effect of simvastatin on lipid droplets accumulation in human embryonic kidney cells and pancreatic cancer cells. Lipids Health Dis 12: 126,2013

62. Ishikawa S, Nagai Y, Masuda T, Koga Y, Nakamura T, Imamura Y, Takamori H, Hirota M, Funakosi A, Fukushima M and $\mathrm{Baba} \mathrm{H}$ : The role of oxysterol binding protein-related protein 5 in pancreatic cancer. Cancer Sci 101: 898-905, 2010.

63. Souchek JJ, Baine MJ, Lin C, Rachagani S, Gupta S, Kaur S, Lester K, Zheng D, Chen S, Smith L, et al: Unbiased analysis of pancreatic cancer radiation resistance reveals cholesterol biosynthesis as a novel target for radiosensitisation. Br J Cancer 111: 1139-1149, 2014.

64. Maione F, Oliaro-Bosso S, Meda C, Di Nicolantonio F, Bussolino F, Balliano G, Viola F and Giraudo E: The cholesterol biosynthesis enzyme oxidosqualene cyclase is a new target to impair tumour angiogenesis and metastasis dissemination. Sci Rep 5: 9054, 2015.

65. Yang Y, Liu H, Li Z, Zhao Z, Yip-Schneider M, Fan Q, Schmidt CM, Chiorean EG, Xie J, Cheng L, et al: Role of fatty acid synthase in gemcitabine and radiation resistance of pancreatic cancers. Int J Biochem Mol Biol 2: 89-98, 2011

66. Hussein D and Mo H: d- $\delta$-Tocotrienol-mediated suppression of the proliferation of human PANC-1, MIA PaCa-2, and BxPC-3 pancreatic carcinoma cells. Pancreas 38: e124-e136, 2009.

67. Shin-Kang S, Ramsauer VP, Lightner J, Chakraborty K, Stone W, Campbell S, Reddy SA and Krishnan K: Tocotrienols inhibit AKT and ERK activation and suppress pancreatic cancer cell proliferation by suppressing the ErbB2 pathway. Free Radic Biol Med 51: 1164-1174, 2011.

68. Guillaumond F, Bidaut G, Ouaissi M, Servais S, Gouirand V, Olivares O, Lac S, Borge L, Roques J, Gayet O, et al: Cholesterol uptake disruption, in association with chemotherapy, is a promising combined metabolic therapy for pancreatic adenocarcinoma. Proc Natl Acad Sci USA 112: 2473-2478, 2015.

69. Menter DG, Ramsauer VP, Harirforoosh S, Chakraborty K, Yang P, Hsi L, Newman RA and Krishnan K: Differential effects of pravastatin and simvastatin on the growth of tumor cells from different organ sites. PLoS One 6: e28813, 2011

70. Gbelcová H, Lenícek M, Zelenka J, Knejzlík Z, Dvoráková G, Zadinová M, Poucková P, Kudla M, Balaz P, Ruml T and Vítek L: Differences in antitumor effects of various statins on human pancreatic cancer. Int J Cancer 122: 1214-1221, 2008.

71. Hong JY, Nam EM, Lee J, Park JO, Lee SC, Song SY, Choi SH, Heo JS, Park SH, Lim HY, et al: Randomized double-blinded, placebo-controlled phase II trial of simvastatin and gemcitabine in advanced pancreatic cancer patients. Cancer Chemother Pharmacol 73: 125-130, 2014.

72. Swierczynski J, Hebanowska A and Sledzinski T: Role of abnormal lipid metabolism in development, progression, diagnosis and therapy of pancreatic cancer. World J Gastroenterol 20: 2279-2303, 2014.

73. Søreide K and Sund M: Epidemiological-molecular evidence of metabolic reprogramming on proliferation, autophagy and cell signaling in pancreas cancer. Cancer Lett 356: 281-288, 2015 . 